2015-09

Non-transferrin-bound iron is associated with biomarkers of oxidative stress, inflammation and endothelial dysfunction in type 2 diabetes

Aljwaid, $\mathrm{H}$

http://hdl.handle.net/10026.1/4172

10.1016/j.jdiacomp.2015.05.017

Journal of Diabetes and its Complications

Elsevier BV

All content in PEARL is protected by copyright law. Author manuscripts are made available in accordance with publisher policies. Please cite only the published version using the details provided on the item record or document. In the absence of an open licence (e.g. Creative Commons), permissions for further reuse of content should be sought from the publisher or author. 


\title{
Non-transferrin-bound iron is associated with biomarkers of oxidative stress, inflammation and endothelial dysfunction in type 2 diabetes
}

\author{
Husam Aljwaid $^{\mathrm{a}, 1}$, Desley L. White ${ }^{\mathrm{b}, 2}$, Keith J. Collard ${ }^{\mathrm{b}, *}$, A. John Moody ${ }^{\mathrm{a}, 3}$, Jonathan H. Pinkney ${ }^{\mathrm{c}, 4}$ \\ a School of Biological Sciences, Faculty of Science \& Environment, University of Plymouth, Drake Circus, Plymouth, PL4 8AA, UK \\ ${ }^{b}$ School of Health Professions, Faculty of Health \& Human Sciences, University of Plymouth, Derriford Road, Plymouth, UK \\ c Centre for Biomedical Research, Translational and Stratified Medicine, Peninsula Schools of Medicine E Dentistry, Plymouth, UK
}

\section{A R T I C L E I N F O}

\section{Article history:}

Received 24 February 2015

Received in revised form 14 May 2015

Accepted 18 May 2015

Available online $\mathrm{xxxx}$

\section{Keywords:}

Obesity

Type 2 diabetes

Cardiovascular disease

Endothelial dysfunction

Non-transferrin-bound iron

Oxidative stress

\begin{abstract}
A B S T R A C T
Aims: To investigate the association between circulating non-transferrin-bound iron [NTBI], and markers of oxidative stress, endothelial function and inflammation in subjects with type 2 diabetes and non-diabetic subjects with varying degrees of obesity.

Methods: Plasma NTBI was measured by HPLC, together with total iron, iron-binding capacity, transferrin saturation and soluble transferrin receptor, together with total and reduced ascorbate, malondialdehyde [MDA], E-selectin and high-sensitivity c-reactive protein [hs-CRP] in groups of 28 subjects with type 2 diabetes, 28 non-obese controls and 17 obese non-diabetic subjects.

Results: Levels of NTBI were higher than controls in the diabetes group, but the total serum iron levels were lower. MDA levels were higher than controls in both the diabetes and obese groups, and this was associated with higher levels of oxidised ascorbate. hs-CRP levels were higher in both the diabetes and obese groups, and E-selectin was significantly higher in the diabetes group. There were strong positive correlations between HbA1c levels and NTBI $[\mathrm{P}<0.01]$, HbA1c and E-selectin $[\mathrm{P}<0.001]$ and NTBI and E-selectin $[\mathrm{P}<0.02]$ in the diabetes group. Conclusion: These results support the hypothesis that iron-mediated oxidative stress may be a mechanism linking poor glycaemic control with vascular dysfunction in type 2 diabetes.
\end{abstract}

(c) 2015 Elsevier Inc. All rights reserved.

\section{Introduction}

Diabetes and obesity are two closely associated conditions both carrying a risk of cardiovascular disease (Hubert, Feinleib, McNamara, \& Castelli, 1983; Kannel \& McGee, 1979). Although many factors are thought to influence the predisposition to cardiovascular disease the underlying mechanisms remain controversial. There is evidence that iron dysregulation may play a significant role in the vascular complications of diabetes, and cardiovascular disease in non-diabetic subjects (Basuli, Stevens, Torti, \& Torti, 2014; Vinchi et al., 2014). In general, most studies have shown evidence of excessive iron stores in subjects with diabetes, while obese subjects tend to be iron deficient using standard methods of assessment (Yanoff et al., 2007; Zafon, Lecube, \& Sim , 2010).

\footnotetext{
Conflict of interest: The authors declare no conflict of interest with regard to this work. * Corresponding author at: Food and Nutrition Unit, Link Laboratories, University of Plymouth, Drake Circus, Plymouth, PL4 8AA, UK. Tel.: + 441752 584691; fax: +44 1752584605.

E-mail addresses: husam.aljwaid@plymouth.ac.uk (H. Aljwaid),

desley.white@plymouth.ac.uk (D.L.White), keith.collard@plymouth.ac.uk (K.J. Collard), j.moody@plymouth.ac.uk (A.J. Moody), jonathan.pinkney@plymouth.ac.uk

(J.H. Pinkney).

1 Tel.: + 447760971704 .

2 Tel.: + 441752587592 .

3 Tel.: + 441752584640 .

4 Tel.: +441752 763498
}

However, the most appropriate methods to measure iron status and its potential impact on CVD risk are currently unclear.

Body iron is known to be present in a number of forms (Waldvogel-Abramowski et al., 2014), not all of which are available to contribute to the development of atherosclerosis or endothelial dysfunction. Within the body iron pool, it is generally considered that iron which is not sequestered on transferrin or bound to other iron-binding proteins, referred to as non-transferrin-bound iron [NTBI] contains a proportion of redox active iron capable of inducing oxidative damage to cells and tissues (Brissot, Ropert, Le Lan, \& Loréal, 2012). This is a relatively small component of total iron stores but is potentially highly reactive (Brissot et al., 2012). The exact nature of NTBI remains to be elucidated, although it is considered that iron complexed with citrate may represent the major form (Brissot et al., 2012). Under certain conditions iron-citrate complexes are redox active and may contribute to oxidative damage to tissues (Adam, Bounds, Kissner, \& Koppenol, 2015). Standard biomarkers for iron status such as ferritin and soluble transferrin receptor concentrations do not necessarily provide an accurate monitor of NTBI levels. In some cases changes in NTBI levels do follow changes in the levels of the standard biomarkers (Goto et al., 2013), but in others this is not so (Porter et al., 2014). Such findings have led to the suggestion that NTBI should be included as a valid independent biomarker of the 
potential adverse effects of iron in disease states (Lee \& Jacobs, 2004; Taher et al., 2009).

The aim of this study, therefore, was to test the hypothesis that NTBI is a biomarker associated with indices of oxidative stress, inflammation and vascular dysfunction in individuals with type 2 diabetes and also in non-diabetic subjects with varying levels of obesity.

\section{Materials and methods}

\subsection{Subjects}

The study was approved by the National Health Service research ethics committee, and participants gave written informed consent. The study was conducted in accordance with the principles of the Declaration of Helsinki and Committee on the Harmonisation of Good Clinical Practice (Dixon, 1999). The study population was comprised of 73 subjects all aged $>40$ years: 28 had type 2 diabetes, recruited from diabetes clinics, 28 were lean healthy control subjects recruited by advertisement, and 17 were obese non-diabetic subjects recruited from diabetes clinics; 17 were obese non-diabetic subjects recruited from the general population and weight management clinics. Based on conservative assumptions on mean and standard deviation for NTBI measurements from previously published data (Lee et al., 2006) we estimated that a sample size of 23 subjects per group would give at least $90 \%$ power to detect a significant difference in NTBI between the diabetic and comparator control groups at the 5\% significance level (http://www.stat.ubc.ca/-rollin/stats/ssize/). In support of this calculation, Leoncini et al. (2008) reported significant differences in NTBI levels between controls and subjects with diabetes using 24 subjects per group. We therefore set a recruitment target of 30 subjects per group, which would allow for up to $20 \%$ drop-outs.

Patients with diabetes had been suffering from the condition for 1-22 years post-diagnosis (mean \pm SD: $9.79 \pm 5.24$ years). Recruitment occurred between November 2012 and November 2013. All diabetic subjects were receiving treatment to improve insulin sensitivity. Most (23) received metformin while others were treated with related drugs e.g., ploglitazone. Some subjects (12) also received treatment to improve insulin secretion, while others (7) received insulin or insulin substitute therapy. Only two of the subjects were treated for other morbidities, one for heart disease and one for asthma/COPD.

Anthropometric indices were measured which included BMI, body fat percentage (Tanita TBF-300MA Body Composition analyser, Tanita UK) and waist-to-hip ratio in a single visit. Each subject supplied $3 \times 3 \mathrm{ml}$ blood samples using Vacutainers (Becton Dickinson, Plymouth, UK), one with lithium heparin as anticoagulant, one with EDTA as anticoagulant and one plain tube for serum. Blood samples in EDTA and lithium heparin tubes were centrifuged at $1,000 \times g$ for $5 \mathrm{~min}$ to provide plasma; the blood in the plain tubes was centrifuged after $30 \mathrm{~min}$ at room temperature, and then plasma and serum were stored at $-80{ }^{\circ} \mathrm{C}$ prior to biochemical analysis. From the EDTA plasma $400 \mu \mathrm{l}$ were removed and added to $400 \mu \mathrm{l}$ of $10 \%$ metaphosphoric acid (MPA) containing $2 \mathrm{mM}$ EDTA and then centrifuged at 20,000 $\times \mathrm{g}$ at $4{ }^{\circ} \mathrm{C}$ for $10 \mathrm{~min}$. The supernatant was removed and stored at $-80{ }^{\circ} \mathrm{C}$ prior to the measurement of ascorbate.

\subsection{Materials}

Light magnesium carbonate, disodium EDTA, metaphosphoric acid, acetonitrile, ethanol, $\mathrm{KCl}, \mathrm{KH}_{2} \mathrm{PO}_{4}, \mathrm{NaCl}, \mathrm{Na}_{2} \mathrm{HPO}_{4} \cdot 12 \mathrm{H}_{2} \mathrm{O}, \mathrm{FeCl}_{3} \cdot 6 \mathrm{H}_{2} \mathrm{O}$, Tris(2-carboxyethyl) phosphine hydrochloride (TCEP), phosphoric acid, 1,2-dimethyl-3-hydroxy-4(1H)-pyridinone (DHP), nitrilotriacetic acid (NTA), butylated hydroxytoluene, thiobarbituric acid and all other laboratory reagents were obtained from Sigma-Aldrich (Poole, UK) or Fisher Scientific (Loughborough, UK). Amicon Ultra filter units $(0.5 \mathrm{ml}$, $30 \mathrm{kDa}$ cut off) were purchased form Merck-Millipore (Fisher Scientific Loughborough, UK). ELISA kits for the measurement of E-Selectin and hsCRP were obtained from Biorbyt, UK. The ELISA kit for the measurement of soluble transferrin receptor was obtained from Biovendor, UK.

\subsection{Measurement of total iron and total iron-binding capacity}

Total iron and total iron-binding capacity were assessed by a scaled down version of the methods recommended by the International Committee for Standardisation in Haematology as described previously (Collard, White, \& Copplestone, 2014). $400 \mu$ of extracellular phase, blanks and standards were added to $400 \mu \mathrm{l}$ of protein precipitation solution (0.6 M TCA and $0.4 \mathrm{M}$ thioglycolic acid in $1 \mathrm{M}$ $\mathrm{HCl}$ ). This was mixed thoroughly for 1 minute and incubated at $56{ }^{\circ} \mathrm{C}$ for 15 minutes in a water bath. The samples were cooled and centrifuged for 5 minutes at $1,000 \times g$ to provide an optically clear supernatant. $500 \mu \mathrm{l}$ of this was added to $500 \mu \mathrm{l}$ of ferene $0.5 \mathrm{mM}$ \{3-(2-pyridyl-5,6-bis-[2-5-furyl sulphonic acid]-1,2,4 triazine $\}$ in $1.5 \mathrm{M}$ sodium acetate. This was incubated for 5 minutes before absorbance was measured at $593 \mathrm{~nm}$ in a spectrophotometer. Iron concentration was computed from the absorbance of standards included in each batch of samples.

To determine iron-binding capacity, $350 \mu \mathrm{l}$ of plasma was added to $350 \mu \mathrm{l}$ of iron saturating solution $(100 \mu \mathrm{M} \mathrm{FeCl}$ in $5 \mathrm{mM} \mathrm{HCl})$. This was mixed and allowed to stand at room temperature for 5 minutes. $35 \mathrm{mg}$ of light magnesium carbonate was then added, and the mixture agitated for 30 minutes. The magnesium carbonate was then removed by two sequential centrifugation steps of $1,000 \times \mathrm{g}$ for 5 minutes. $400 \mu \mathrm{l}$ of the resultant supernatant was removed for the measurement of iron as described above.

\subsection{Measurement of non-transferrin-bound iron [NTBI]}

NTBI was measured using a slight modification of the HPLC method of Kime, Gibson, Yong, Hider, and Powers (1996). Briefly, $300 \mu \mathrm{l}$ of plasma was incubated with $30 \mu \mathrm{l}$ of $0.8 \mathrm{M}$ nitrilotriacetic acid [NTA] for 20 minutes at room temperature to chelate loosely bound iron, such as that chelated with residual citrate or albumin. The samples were then placed in $30 \mathrm{kDa}$ Amicon Ultra $0.5 \mathrm{ml}$ filters (Millipore) and centrifuged at $13,000 \times g$ at $4{ }^{\circ} \mathrm{C}$ for 30 minutes. $250 \mu$ of the ultrafiltrate were removed and incubated with $25 \mu \mathrm{l}$ of $35 \mathrm{mM}$ 3-hydroxy-1-propyl-2methyl-pyridon-4-one for 5 minutes before injecting into the HPLC system (sample loop $20 \mu \mathrm{l}$ ). The mobile phase consisted of $5 \mathrm{mM}$ PIPES buffer pH7.0 containing 3.5 mM 3-hydroxy-1-propyl-2-methyl-pyridon-4-one and $5 \%$ acetonitrile. The column was a PEEK lined $100 \mathrm{~mm} \times 5 \mathrm{~mm} \mathrm{C18}$ column (Hichrom). All tubing was PEEK. The mobile phase was pumped at a flow rate of $1 \mathrm{ml} /$ minute using a Dionex pump. The absorbance of the iron-chromophore complex was determined using a Dionex UV/VIS detector at a wavelength of $450 \mathrm{~nm}$, and chromatography conducted using Chromeleon software. The concentration of NTBI was computed from blanks and standards taken through the whole procedure with each batch of samples. The coefficient of variation calculated using a range of NTBI concentrations over a number of days ranged from $3.79 \%$ to $7.50 \%$.

\subsection{Measurement of ascorbate}

Total and oxidised ascorbate were measured by the method of Sato et al. (2010). Two aliquots of $90 \mu \mathrm{l}$ were removed from the initial MPA extract. To one of these $10 \mu \mathrm{l}$ of 5\% MPA were added. A further $200 \mu \mathrm{l}$ of $5 \%$ MPA was added, the sample mixed and injected into the HPLC system ( $20 \mu \mathrm{l}$ sample loop). This provided the value for reduced ascorbate. To the other aliquot, $10 \mu \mathrm{l}$ of tris (2-carboxyethyl) phosphine hydrochloride [TCEP] was added, and the mixture incubated at room temperature for 20 minutes to convert all the oxidised ascorbate to the reduced form. $200 \mu \mathrm{l}$ of $5 \%$ MPA was then added, the sample mixed and injected into the HPLC system. This provided a measure of total 
ascorbate. The degree of ascorbate oxidation was computed by subtracting the value for reduced ascorbate from that of the total ascorbate.

The HPLC system consisted of a $150 \mathrm{~mm} \times 4.6 \mathrm{~mm}$ ACE 5 AQ C18 column (Hichrom, Reading UK), a Milton Roy Constametric pump (Milton Roy, Sunderland UK) coupled to a BAS LCD40 electrochemical detector (BASi West Lafayette IN, USA) set at a voltage of $+0.6 \mathrm{~V}$. The mobile phase consisted of $50 \mathrm{mM}$ phosphate buffer containing $0.54 \mathrm{mM}$ EDTA and $2 \%$ methanol at a $\mathrm{pH}$ of 2.8 . This was pumped at $1.0 \mathrm{ml} /$ minute.

\subsection{Measurement of malondialdehyde [MDA]}

This was measured in this study by the method of Agarwal and Chase (2002) as described previously (Collard et al., 2014). Plasma $(50 \mu \mathrm{l}$ ) or standard (up to $2 \mu \mathrm{M}$ ) or blank was mixed with $50 \mu \mathrm{l}$ of BHT ( $0.05 \%$ in $95 \%$ ethanol), $400 \mu \mathrm{l}$ of phosphoric acid $(0.44 \mathrm{M})$ and $100 \mu \mathrm{l}$ of TBA ( $42 \mathrm{mM}$ ). The tubes were capped and the contents mixed well on a vortex mixer. All tubes were heated for $1 \mathrm{~h}$ at $100{ }^{\circ} \mathrm{C}$ in a dry block, and then were removed and placed on ice to cool. Butan-1-ol ( $300 \mu \mathrm{l}$ ) was added and mixed well using the vortex mixer. The mixture was centrifuged for $5 \mathrm{~min}$ at $13,000 \times g$ to separate the aqueous and butanol phases. Two hundred microliters of the butanol extract were removed carefully and placed in tubes ready for injection directly into a Dionex Ultimate 3000 HPLC system (Thermo Fisher Scientific) comprising an Ultimate 3000 pump and Ultimate 3000 fluorescence detector. Chromatography was conducted using a $100 \mathrm{~mm} \times 4.6 \mathrm{~mm}$ Hichrom $\mathrm{C}_{18}$ column, protected by a guard column of the same resin and a $2 \mu \mathrm{m}$ inline filter (Hichrom). Chromatography was controlled using Chromeleon software (version 6.8) (Thermo Fisher Scientific). The mobile phase (50 $\mathrm{mM}$ potassium phosphate/methanol $80: 20 \mathrm{v} / \mathrm{v}, \mathrm{pH} 6.8$ ) was pumped at a rate of $1.0 \mathrm{ml} \mathrm{min}^{-1}$. MDA was detected using an excitation wavelength of $515 \mathrm{~nm}$ and an emission wavelength of $553 \mathrm{~nm}$.

\subsection{Assessment of endothelial function}

This was determined by the measurement of circulating E-selectin (Endothelial Leukocyte Adhesion Molecule-1, ELAM-1). E-selectin was measured by a commercially available ELISA kit (Biorbyt UK) according to the manufacturer's instructions. The sensitivity of the assay was $<10 \mathrm{pg} / \mathrm{ml}$ with a dynamic range of $62.5 \mathrm{pg} / \mathrm{ml}-4,000 \mathrm{pg} / \mathrm{ml}$. The assay showed no cross reactivity with any cytokine (manufacturer's data).

\subsection{Measurement of $\mathrm{C}$-reactive protein}

C-reactive protein was measured using a commercially available ELISA kit (Biorbyt UK) according to the manufacturer's instructions. The sensitivity of the assay was $<10 \mathrm{pg} / \mathrm{ml}$ with a dynamic range of $156 \mathrm{pg} / \mathrm{ml}-10,000 \mathrm{pg} / \mathrm{ml}$. The assay was specific for natural and recombinant CRP (manufacturer's data).

\subsection{Iron status}

Serum soluble transferrin receptor [sTfR] concentration, a measure of iron status was assessed using a commercially available ELISA kit (BioVendor UK) according to the manufacturers' instructions. The sensitivity of the assay was $5 \mathrm{ng} / \mathrm{ml}$ with a dynamic range of $5 \mathrm{ng} / \mathrm{ml}-10 \mu \mathrm{g} / \mathrm{ml}$. The assay was specific for human sTfR with no cross reaction with sTfR from other species. The intra-assay CV was $6.0-7.5 \%$. The inter assay CV was $5.5-7.0 \%$ (manufacturer's data).

\subsection{Measurement of HbA1c}

Glycated haemoglobin (HbA1c) was measured by cation exchange high-pressure liquid chromatography on a Menarini Biomen HA-8160 analyser. CVs were $1.2 \%$ for $\mathrm{HbA} 1 \mathrm{c} 6 \%$ ( $42 \mathrm{mmol} / \mathrm{mol}$ ) and $1.1 \%$ for HbA1c 11\% (97 mmol/mol).

\subsection{Data analysis and statistics}

Statistical testing was carried out using IBM SPSS 21. Data were tested for normality using Shapiro-Wilk. Normally distributed data were tested for differences between groups using ANOVA, with Bonferroni post-hoc tests. Non-parametric data were tested using Mann-Whitney U. All tests were 2-tailed, with $p$ set at $\leq 0.05$. Correlational data were analysed using the Pearson test. There was a small but significant difference in the mean ages of the three groups of subjects (Table 1 ). In view of this it was necessary to determine the influence of this mismatch on the data. This was done by inserting the data into a general linear model with subject age as a quantitative factor and subject group as a qualitative factor. In all cases there was no significant interaction between subject age and subject group.

\section{Results}

\subsection{Sample groups}

There was no correlation between age and any of the parameters measured except for total iron-binding capacity which declined with age $(\mathrm{r}=0.344: \mathrm{P}<0.01)$.

\subsection{Indices of iron status}

The measures of iron status are shown in Fig. 1 (charts a-f). In the diabetes group compared to the control group NTBI, sTfR, and transferrin saturation were elevated, while total serum iron and TIBC were lower. NTBI levels and transferrin saturation were higher in the diabetes group compared to the obese group. The NTBI levels were not significantly higher in the obese group compared to controls, but sTfR levels were elevated.

Table 1

Demographic details of subjects.

\begin{tabular}{|c|c|c|c|}
\hline & Lean controls & Type 2 diabetes & Obese controls \\
\hline No of subjects & 28 & 28 & 17 \\
\hline Age $[$ mean $\pm \mathrm{SD}]$ & $51.2 \pm 6.6^{\dagger}$ & $57.8 \pm 6.8^{\Delta}$ & $49.5 \pm 9.0$ \\
\hline Sex & F7, M21 & F10, M18 & F9, M8 \\
\hline BMI $[$ mean $\pm S D]$ & $22.88 \pm 1.71^{\dagger}$ & $34.25 \pm 8.48^{\Delta}$ & $38.17 \pm 6.35$ \\
\hline Waist:Hip ratio [mean \pm SD] & $0.851 \pm 0.079^{\dagger}$ & $1.015 \pm 0.274^{\Delta}$ & $0.916 \pm 0.076$ \\
\hline$\%$ Body fat $[$ mean \pm SD] & $20.71 \pm 5.10^{\dagger}$ & $35.79 \pm 10.33^{\Delta}$ & $41.13 \pm 8.73$ \\
\hline HbA1c concentration & & $65.75 \pm 19.56 \mathrm{mmol} / \mathrm{mol} 8.164 \pm 1.79 \%$ & \\
\hline
\end{tabular}

Data were analysed by ANOVA with Bonferroni post-hoc tests. Significance was set at $\mathrm{P}<0.05$.

Significant differences between groups are shown as follows:

between controls and subjects with diabetes; $\dagger$ between controls and obese subjects; $\Delta$ between subjects with diabetes and obese subjects. 

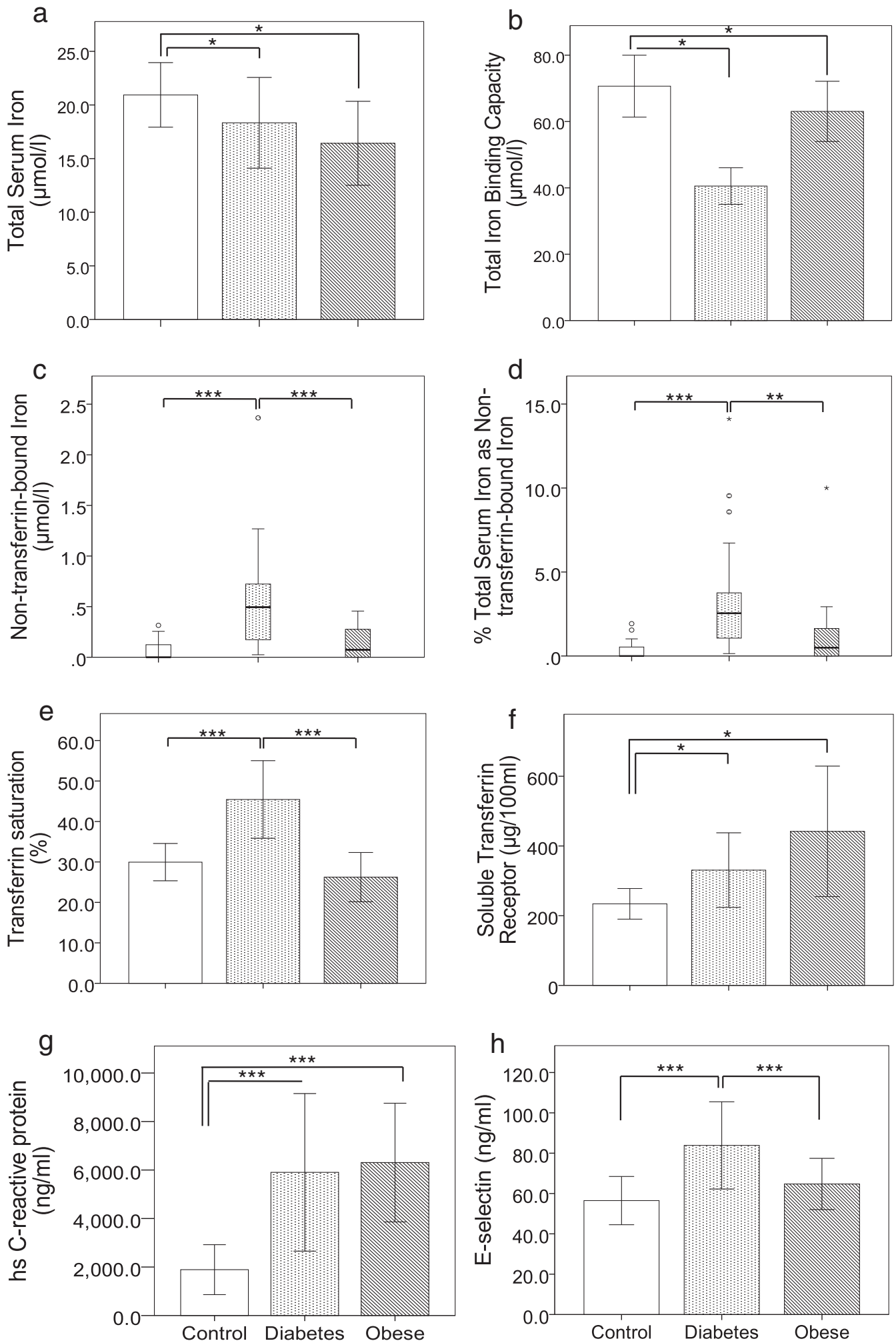

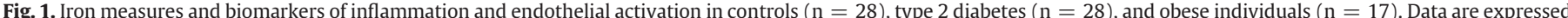

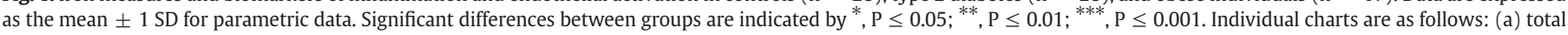

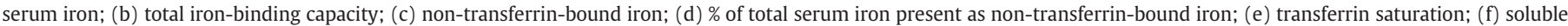
transferrin receptor; (g) high-sensitivity C-reactive protein; (h) E-selectin.

\subsection{Biomarkers of oxidative status}

Biomarkers of oxidative stress are presented in Table 2. The levels of MDA, oxidised ascorbate, hsCRP and E-selectin were higher in the diabetes group than in controls, while the level of reduced ascorbate was lower. Similarly, the levels of MDA, oxidised ascorbate and hsCRP were higher in the obese subjects than controls, but E-selectin levels were similar. MDA and E-selectin levels were higher in the diabetes 
Table 2

Biomarkers of oxidative stress.

\begin{tabular}{lrcc}
\hline & \multicolumn{1}{c}{ Controls } & \multicolumn{1}{c}{ Diabetes } & \multicolumn{1}{c}{ Obese } \\
\hline MDA [ $\mu \mathrm{mol} / \mathrm{l}]$ & $0.946 \pm 0.182^{\dagger}$ & $1.665 \pm 0.454^{\Delta}$ & $1.215 \pm 0.282$ \\
Total ascorbate $[\mu \mathrm{mol} / \mathrm{l}]$ & $66.971 \pm 27.185$ & $47.100 \pm 16.923^{\Delta}$ & $72.732 \pm 26.226$ \\
Oxidised ascorbate $[\mu \mathrm{mol} / \mathrm{l}]$ & $6.507 \pm 3.318^{\dagger}$ & $10.337 \pm 7.132^{\Delta}$ & $16.139 \pm 13.128$ \\
\% Oxidised ascorbate & $11.314 \pm 7.037^{\dagger}$ & $22.765 \pm 14.859$ & $20.434 \pm 12.556$ \\
Ratio of oxidised: & $0.135 \pm 0.103^{\dagger}$ & $0.340 \pm 0.300^{\Delta}$ & $0.291 \pm 0.220$ \\
$\quad$ & & \\
\hline Reduced ascorbate & & & \\
\hline
\end{tabular}

Data are expressed as the mean \pm SD of 28 subjects (diabetes and control groups) and 17 (obese subjects).

Significant differences between groups are shown as follows:

between controls and subjects with diabetes; $\dagger$ between controls and obese subjects; $\Delta$ between subjects with diabetes and obese subjects.

subjects than those in the obese group. The ratio of oxidised to reduced ascorbate was highest in the diabetes group, which was significantly higher than that of the obese group. Both obese and diabetes groups had higher oxidised to reduced ratios than the controls.

\subsection{Biomarkers of endothelial function and immune status}

Biomarkers of endothelial activation and inflammation are shown in Fig. 1 (charts g and h). E-selectin levels were significantly higher in the diabetes group than the controls and obese subjects which were not significantly different. The level of hs-CRP was significantly higher in the diabetes and obese groups than controls.

\subsection{Correlation between iron status and parameters of oxidative status, immune function and endothelial activity}

An important finding of this study was the strong positive correlation between HbA1c level and NTBI in the diabetic group $(\mathrm{R}=0.521 ; \mathrm{P}<0.01)$. There was also a strong positive correlation between NTBI and E-selectin in this group $(\mathrm{R}=0.850$; $\mathrm{P}<0.001)$, but not in the other groups. HBA1c also correlated with E-selectin in the diabetic group $(\mathrm{R}=0.469 ; \mathrm{P}<0.02)$.

\section{Discussion}

There has been considerable interest in the potential role of iron in diabetes and its complications (Basuli et al., 2014; White \& Collinson, 2013), but the complex interactions between iron, reactive oxygen species and the development of diabetes and its complications are not fully understood (Simcox \& McClain, 2013). The results of this study have provided strong evidence of the association of NTBI with the risk of vascular complications of type 2 diabetes.

With regard to overall iron status, the high level of circulating sTfRs in the obese group is consistent with previous observations of iron deficiency in obesity (Ausk \& Ioannou, 2008; Capeda-Lopez et al., 2011). The higher sTfR levels seen in the diabetes group would also imply iron deficiency which is contrary to the findings of many previous studies (see Simcox \& McClain, 2013). The majority of circulating sTfRs originate from erythroblasts and reticulocytes (Beguin, 2003). However, other cells which accumulate iron and also express sTfRs include adipocytes. Furthermore the expression of sTfRs in adipocytes is enhanced by insulin treatment (Tanner \& Lienhard, 1987). The diabetic subjects were insulin resistant, overweight and probably hyperinsulinaemic. Hence it may be suggested that enhanced iron uptake by adipocytes in these individuals might contribute to the enhanced circulating sTfRs rather than evidence of iron deficiency.

The high level of NTBI observed in the diabetes group in this study is in agreement with those of Sulieman et al. (2004), Lee et al. (2006) and Leoncini et al. (2008), but not Van Campenhaut et al. (2006). Of the methods used to measure NTBI, HPLC has been suggested to be the 'gold standard' with regard to sensitivity and specificity (Sasaki et al.,
2011). The HPLC method used in this study incorporated a number of the refinements suggested by Sasaki et al. (2011) to optimise the methodology, and reported similar limits of sensitivity, and mean values as seen in our control group. Consequently we are confident that the NTBI measurements made in this study are an accurate measure of the availability of circulating iron which is not sequestered with macromolecules.

Elevated circulating levels of NTBI in the diabetic group could have arisen as a result of poor binding of iron by iron-binding proteins or as a result of excessive iron entering the circulation from other sources. In this study, the amount of iron bound to transferrin in subjects with diabetes was greater than that seen in controls or obese subjects, suggesting that decreased iron chelation by iron-binding proteins may not be the cause of the elevated NTBI. The strong positive correlation between HbA1c and NTBI levels in the diabetic subjects suggests that NTBI availability may be related to the degree of protein glycation. Protein glycation may in turn lead to the formation of reactive oxygen species (Resmi, Akhunlar, Temez Artmann, \& Guner, 2005). A number of glycated proteins have been identified within the RBC membrane of diabetic patients (Zhang et al., 2011). Glycation of cell surface proteins of the RBC membrane modifies the visco-elastic properties of the RBCs which decreases their deformability (Riquelme, Foresto, D’Arrigo, Valverde, \& Rasia, 2005) and ability to pass through fine vessels (Starodubtseva, Kuznetsova, Yegorenkov, \& Cherenkevich, 2008). These changes may predispose patients with type 2 diabetes to an enhanced tendency towards intravascular haemolysis. This would permit the efflux of glycated/oxidatively modified intracellular components such as $\mathrm{Hb}$ and heme which may release free iron (Collard \& White, 2014; Maitra et al., 2011). The changes in MDA and ascorbate seen in the diabetes group indicate that there is a high level of oxidative stress occurring in these subjects. Thus, it is possible to speculate that the increase in NTBI observed in subjects with diabetes may have derived not from an inability to sequester free iron but from the functional consequences of protein glycation and oxidative modification of RBCs.

Changes in RBC deformability in a rat model of diabetes occur before the development of vascular complications (Diamantopoulos et al., 2004), indicating that the consequences of RBC membrane dysfunction, as described above, may trigger the vascular events. Endothelial dysfunction is considered to be the earliest event in atherogenesis. The strong positive correlation between NTBI and E-selectin in the diabetic group suggests that endothelial function may be influenced by circulating free iron. This is supported by previous studies which showed that the administration of iron to healthy individuals induced endothelial dysfunction which was associated with increased free radical generation (Rooyakkers et al., 2002) while chelation of iron with deferroxamine led to decreased induction of E-selectin and other adhesion molecules in an in vitro model of endothelial activation (Zhang \& Frei, 2003). There was a positive relationship between these parameters in the obese group, but it did not reach significance. This therefore requires further study with a larger group of obese subjects.

The high levels of inflammation seen in both the obese and diabetic subjects may also contribute to iron-mediated vascular dysfunction. Part of the inflammatory process includes the enhancement of hepcidin secretion (Ganz \& Nemeth, 2009; Nemeth et al., 2003). Hepcidin inhibits the efflux of iron from macrophages (Knutson, Oukka, Koss, Aydemir, \& Wessling-Resnick, 2005). These iron-rich macrophages can enter the developing atherosclerotic plaque and contribute to iron-induced pathology (Vinchi et al., 2014). The failure to observe a significantly increased NTBI level in obese subjects, and a lack of correlation between NTBI and E-selectin in this group suggests that circulating NTBI may not be a major atherogenic factor in obese subjects. On the other hand, locally released iron from macrophages incorporated into the developing atherosclerotic plaque might be a more likely source (Basuli et al., 2014; Vinchi et al., 2014). In contrast, while adipokine-mediated inflammation and endothelial dysfunction would, in all probability, 
also be operating in the diabetic group, the higher levels of endothelial activation, oxidative stress and NTBI suggest that the diabetic group may have an enhanced tendency to develop atherosclerosis which may be related to iron-mediated phenomena resulting from haemolysis as outlined above.

In conclusion, the results of this study have extended our knowledge of the relationship between iron and iron-associated substances and other factors involved in the vascular complications of diabetes. This has allowed the development of a hypothetical sequence of events to account for these interactions and which may be investigated by further study. The data would support a scenario in which the source of the iron and iron-containing substances is likely to be the erythrocyte, and it may be proposed that this derives from a degree of intravascular haemolysis resulting from glycation-mediated changes in the elasticity and deformability of the erythrocyte membrane. The released iron and iron-containing molecules then contribute to endothelial dysfunction by promoting oxidative damage and other deleterious processes involved in atherogenesis (Vinchi \& Tolosano, 2013; Vinchi et al., 2014). In contrast, the potential involvement of iron dysregulation in the vascular complications of obesity is less evident from our data.

\section{Strengths and limitations of the study}

The study has a number of strengths and some weaknesses. The major strength of this study was the measurement of a panel of key parameters in a single subject. This allowed a more comprehensive analysis of the relationships between the parameters, and provided the opportunity to develop a working hypothesis of the possible link between glucose control, iron and atherogenesis in diabetes. The weakness of the study was the cross-sectional design and limited sample size, particularly of the obese group, treatment heterogeneity and the slight difference in the age of the participants in the groups. Consequently, the sequence of events proposed remains hypothetical.

\section{Acknowledgements}

We would like to thank all the subjects for kindly participating in the study. The technical support of Liz Preston and Natalie Sweet is gratefully acknowledged. HA was supported by a doctoral bursary from the Government of Iraq. DLW was in receipt of a Plymouth University Faculty of Health Dean's Scholarship.

\section{References}

Adam, F. I., Bounds, P. L., Kissner, R., \& Koppenol, W. H. (2015). Redox properties and activity of iron-citrate complexes: Evidence for redox cycling. Chemical Research in Toxicology, 28, 604-614.

Agarwal, R., \& Chase, S. D. (2002). Rapid, fluorimetric-liquid chromatographic determination of malondialdehyde in biological samples. Journal of Chromatography B, Analytical Technologies in the Biomedical and Life Sciences, 775, $121-126$.

Ausk, K. J., \& Ioannou, G. N. (2008). Is obesity associated with anaemia of chronic disease? A population study. Obesity (Silver Spring), 16, 2356-2361.

Basuli, D., Stevens, R. G., Torti, F. M., \& Torti, S. V. (2014). Epidemiological associations between iron and cardiovascular disease and diabetes. Frontiers in Pharmacology, 2014(5), 177-186.

Beguin, Y. (2003). Soluble transferrin receptor for the evaluation of erythropoiesis and iron status. Clinica Chimica Acta, 329, 9-22.

Brissot, P., Ropert, M., Le Lan, C., \& Loréal, O. (2012). Non-transferrin bound iron: A key role in iron overload and iron toxicity. Biochimica et Biophysica Acta, 1820, 403-410.

Capeda-Lopez, A. C., Osendarp, S. J., Melse-Boonstra, A., Aeberli, I., Gonzalez-Salazar, F., Feskins, E., et al. (2011). Sharply higher rates of iron deficiency in obese Mexican women and children predicted by obesity-related inflammation rather than by differences in dietary iron intake. American Journal of Clinical Nutrition, 93, 975-983.

Collard, K. J., \& White, D. L. (2014). On the source of the non-transferrin-bound iron which accumulates in packed red blood cell units during storage. Blood Transfusion, 12, 527-532

Collard, K., White, D., \& Copplestone, A. (2014). The influence of storage age on iron status, oxidative stress and antioxidant protection in paediatric packed cell units. Blood Transfusion, 12, 210-219.
Diamantopoulos, E. J., Kittas, C., Charitos, D., Grigoriadou, E. J., Ifanti, G., \& Raptis, S. A. (2004). Impaired erythrocyte deformability precedes vascular changes in experimental diabetes mellitus. Hormone and Metabolic Research, 36, 142-147.

Dixon, J. R. (1999). The international conference on harmonisation good clinical practice guideline. Quality Assurance, 6, 65-74.

Ganz, T., \& Nemeth, E. (2009). Iron sequestration and anaemia of inflammation. Seminars in Hematology, 46, 387-393.

Goto, T., Ikuta, K., Inamoto, Y., Kamoshita, S., Yokohata, E., Koyama, D., et al. (2013) Hyperferritinemia after adult allogenic hematopoietic cell transplantation: Quantification of iron burden by determining non-transferrin-bound iron. International Journal of Hematology, 97, 125-134.

Hubert, H. B., Feinleib, M., McNamara, P. M., \& Castelli, W. P. (1983). Obesity as an independent risk factor for cardiovascular disease: A 26-year follow up of participants in the Framingham Heart Study. Circulation, 67, 968-977.

Kannel, W. B., \& McGee, D. L. (1979). Diabetes and cardiovascular disease. The Framingham study. JAMA, 241, 2035-2038.

Kime, R., Gibson, A., Yong, W., Hider, R., \& Powers, H. (1996). Chromatographic method for the determination of non-transferrin-bound iron suitable for use on the plasma and bronchoalveolar lavage fluid of preterm babies. Clinical Science (London), 91, 633-638.

Knutson, M. D., Oukka, M., Koss, L. M., Aydemir, F., \& Wessling-Resnick, M. (2005). Iron release from macrophages is up-regulated by ferroportin 1 overexpression and down-regulated by hepcidin. Proceedings of the National Academy of Sciences of the United States of America, 102, 1324-1328.

Lee, D. H., \& Jacobs, D. R. (2004). Serum markers of stored body iron are not appropriate markers of health effects of iron: A focus on serum ferritin. Medical Hypotheses, 62, 442-445.

Lee, D. H., Liu, D. Y., Jacobs, D. R., Shin, H. R., Song, K., Lee, I. K., et al. (2006). Common presence of non-transferrin-bound iron among patients with type 2 diabetes. Diabetes Care, 29, 1090-1095.

Leoncini, S., Rossi, V., Signorini, C., Tanganelli, I., Comporti, M., \& Ciccoli, L. (2008) Oxidative stress, erythrocyte ageing and plasma non-protein-bound iron in diabetic subjects. Free Radical Research, 42, 716-724.

Maitra, D., Byun, J., Andreana, P. R., Abdulhamid, I., Diamond, M. P., Saed, G. M., et al (2011). Reaction of haemoglobin with HOCl: mechanism of heme destruction and free iron release. Free Radical Biology and Medicine, 51, 374-386.

Nemeth, E., Valore, E. V., Territo, M., Schiller, G., Lichtenstein, A., \& Ganz, T. (2003). Hepcidin, a putative mediator of anaemia of inflammation, is a type II acute-phase protein. Blood, 101, 2461-2463.

Porter, J. B., Walter, P. B., Neumayer, L. D., Evans, P., Bansal, S., Garbowski, M., et al. (2014). Mechanisms of plasma non-transferrin-bound iron generation: Insights from comparing transfused diamond blackfan anaemia with sickle cell and thalassaemia patients. British Journal of Haematology, 167, 692-696.

Resmi, H., Akhunlar, H., Temez Artmann, A., \& Guner, G. (2005). In vitro effects of high glucose concentrations on membrane protein oxidation, G-actin and deformability of human erythrocytes. Cell Biochemistry and Function, 23, 163-168.

Riquelme, B., Foresto, P., D’Arrigo, M., Valverde, J., \& Rasia, R. (2005). A dynamic and stationary rheological study of erythrocytes incubated in a glucose medium. Journal of Biochemical and Biophysical Methods, 62, 131-141.

Rooyakkers, T. M., Stroes, E. S. G., Kooistra, M. P., van Faassen, E. E., Hider, R. C., Rabelink T. J., et al. (2002). Ferric saccharate induces oxygen radical stress and endothelia dysfunction in vivo. European Journal of Clinical Investigation, 32, 9-16.

Sasaki, K., Ikuta, K., Tanaka, H., Ohtake, T., Torimoto, Y., Fujiya, M., et al. (2011). Improved quantification for non-transferrin-bound iron measurement using highperformance liquid chromatography by reducing iron contamination. Molecular Medicine Reports, 4, 913-918.

Sato, Y., Uchiki, T., Iwama, M., Kishimoto, Y., Takahashi, R., \& Ishigami, A. (2010). Determination of dehydroascorbic acid in mouse tissues and plasma by using tris(2-carboxyethyl) phosphine hydrochloride as reductant in metasphosphoric acid/ethelenediaminetetraacetic acid solution. Biological and Pharmaceutical Bulletin, 33, 364-369.

Simcox, J. A., \& McClain, D. A. (2013). Iron and diabetes risk. Cell Metabolism, 17, 329-341.

Starodubtseva, M. N., Kuznetsova, T. G., Yegorenkov, N. I., \& Cherenkevich, S. N. (2008) Structural and mechanical characteristics of erythrocyte membranes in patients with type 2 diabetes mellitus. Bulletin of Experimental Biology and Medicine, 145 99-103.

Sulieman, M., Asleh, R, Cabantchik, Z I., Breuer, W Aronson, D., Suleiman, A, et al. (2004). Serum chelatable redox-active iron is an independent predictor of mortality after myocardial infarction in individuals with diabetes. Diabetes Care 27, 2730-2732.

Taher, A., Musallam, K. M., El Rassi, F., Duca, L., Inati, A., Koussa, S., et al. (2009). Levels of non-transferrin-bound iron as an index of iron overload in patients with thalassemia intermedia. British Journal of Haematology, 146, 569-572.

Tanner, L. I., \& Lienhard, G. E. (1987). Insulin elicits a redistribution of transferrin receptors in 3 T3-L1 adipocytes through an increase in the rate constant for receptor externalisation. Journal of Biological Chemistry, 262, 8975-8980.

Van Campenhaut, A., Van Campenhaut, C., Lagrou, A. R., Moorkens, G., De Block, C., \& Manuel-y-Keenoy, B. (2006). Iron-binding antioxidant capacity is impaired in diabetes mellitus. Free Radical Biology and Medicine, 40, 1749-1755.

Vinchi, F., Muckenthaler, M. U., Da Silva, M. C., Balla, G., Balla, J., \& Veney, V. (2014) Atherogenesis and iron: From epidemiology to cellular level. Frontiers in Pharmacology, 5 , 94-113.

Vinchi, F., \& Tolosano, E. (2013). Therapeutic approaches to limit hemolysis-driven endothelial dysfunction: Scavenging free heme to preserve vascular homeostasis. Oxidative Medicine and Cellular Longevity, 396527, 1-11. 
Waldvogel-Abramowski, S., Waeber, G., Gassner, C., Buser, A., Frey, B. M., Favrat, B., et al. (2014). Physiology of iron metabolism. Transfusion Medicine and Hemotherapy, 41, 213-321.

White, D. L., \& Collinson, A. (2013). Red meat, dietary heme iron, and risk of type 2 diabetes: The involvement of advanced lipoxidation endproducts. Advances in Nutrition, $4,404-411$.

Yanoff, L. B., Menzie, C. M., Denlinger, B., Sebring, N. G., McHugh, T., Remalay, A. T., et al. (2007). Inflammation and iron deficiency in the hypoferremia of obesity. International Journal of Obesity, 31, 1412-1419.
Zafon, C., Lecube, A., \& Sim , R. (2010). Iron in obesity. An ancient micronutrient for a modern disease. Obesity Reviews, 11, 322-328.

Zhang, W. J., \& Frei, B. (2003). Intracellular metal ion chelators inhibit TNF- $\alpha$-induced PP-I activation and adhesion molecule expression in human aortic endothelial cells. Free Radical Biology and Medicine, 34, 674-682.

Zhang, Q., Monroe, M. E., Schepmoes, A. A., Clauss, T. R. W., Gritsenko, M. A., Meng, D., et al. (2011). Comprehensive identification of glycated peptides and their glycation motifs in plasma and erythrocytes of control and diabetic subjects. Journal of Proteome Research, 10, 3076-3088. 